\title{
A Partir dos Muros da Universidade: Implementação de uma Clínica Psicanalítica para Crianças Autistas
}

\author{
Maria Gláucia Pires Calzavara ${ }^{1}$ \\ ${ }^{1}$ Universidade Federal de São João del-Rei, MG, Brasil.
}

\author{
Roberto Calazans ${ }^{1}$ \\ ${ }^{1}$ Universidade Federal de São João del-Rei, MG, Brasil.
}

Resumo: Este artigo tem por objetivo apresentar os fundamentos teóricos da implantação de uma clínica de atendimento psicanalítico a crianças autistas em uma Universidade Federal. Aqui, apresentamos como se fundamenta essa clínica, como ela se iniciou, seu funcionamento, sua práxis na instituição e como se dá o tratamento da criança autista no Serviço de Psicologia Aplicada de uma Universidade Federal. O método implica uma discussão sobre o "estado da arte" nesse campo a fim de discutir as bases teóricas e a implementação recente (em 2019) de um serviço de psicanálise pela Universidade Federal de São João del-Rei para crianças autistas, realizado por meio da prática entre vários, método que agrega todas as intervenções realizadas por todos que trabalham com as crianças autistas na instituição. Ressaltamos neste artigo a importância da fundamentação teórica de todo e qualquer trabalho clínico, uma vez que é a partir dela que poderemos orientar os tratamentos disponibilizados para a população em geral, principalmente em tempos em que a saúde pública tem sido precarizada. Concluímos reiterando a necessidade dessa especialidade de trabalho realizado pela psicanálise, em especial a clínica psicanalítica dos autismos, em tempos de massificação do tratamento, que pretende retirar a psicanálise do campo de práticas possíveis de atendimento em políticas públicas de saúde mental.

Palavras-chave: Clínica, Psicanálise, Autismo, Universidade.

\section{From the Walls of the University: Implementation of a Psychiatric Clinic for Autistic Children}

\begin{abstract}
This article presents the theoretical foundations of the implementation of a psychoanalytic clinic for autistic children inside a Federal University. We will present what this clinic is based on, how it started, its operation, its praxis in the institution and how the treatment of the autistic child is performed at the Applied Psychology Service at a Federal University. The method involves a discussion of the "state of art" in this field with the aim of discussing the theoretical bases and the recent implementation (2019) of a psychoanalysis service by the Federal University of São João del-Rei for autistic children by means of the practice among several, as the method that aggregates all the interventions performed by all the people who work with autistic children at the institution. We emphasize in this article the importance of the theoretical basis of any clinical work since it guides the treatments available to the general population, especially in times when public health has been precarious. We conclude by reiterating the necessity of this specialty of work done by psychoanalysis, especially the psychoanalytic clinic of autism in times of mass treatment, which aims to remove psychoanalysis from the field of possible practices of care in public mental health policies.
\end{abstract}

Keywords: Clinic, Psychoanalysis, Autism, University. 


\title{
Más Allá de los Muros de la Universidad: Implementación de una Clínica Psicoanalítica para Niños Autistas
}

\begin{abstract}
Resumen: Este artículo tiene el propósito de presentar los fundamentos teóricos de la implementación de una clínica de asistencia psicoanalítica para niños autistas en el interior de una Universidad Federal. Seguiremos con el objetivo de presentar como se fundamenta esa clínica, como se ha dado su inicio, su operación, su praxis en la institución y, de esa manera, como se da el tratamiento del niño autista en el Servicio de Psicología Aplicada en una Universidad Federal. El método implica una discusión acerca del «estado del arte» en este campo con el objetivo de discutir las bases teóricas y la implementación reciente (2019) de un servicio de psicoanálisis de la Universidad Federal de São João del-Rei para niños autistas a través de la «práctica entre varios», como «método que agrega todas las intervenciones realizadas por todas las personas» que trabajan en la institución para niños autistas. Subrayamos en este artículo la importancia de la fundamentación teórica de todo y cualquier trabajo clínico desde lo cual podremos orientar los tratamientos ofrecidos a la población general, principalmente en tiempos en que la salud pública ha sido precarizada. Concluimos reiterando esa especialidad de trabajo realizado por el psicoanálisis, en especial la clínica psicoanalítica de los autismos en tiempos de masificación del tratamiento, que pretende quitar el psicoanálisis del campo de prácticas posibles de asistencia en políticas públicas de salud mental.
\end{abstract}

Palabras clave: Clínica, Psicoanálisis, Autismo, Universidad.

\section{Introdução}

Como implantar uma clínica psicanalítica para tratamento de crianças autistas e seus familiares em uma instituição de ensino superior no Brasil? Qual fundamentação teórica permite a permanência dessa clínica no âmbito da psicanálise e quais invenções dentro do contexto institucional são necessárias, principalmente quando essa instituição de ensino superior se localiza no interior de Minas Gerais, em uma cidade que, como já demonstrado, tem dificuldades para implantação da política de saúde mental (Pontes, Lopes, Santos, \& Calazans, 2014), particularmente de saúde mental infantil? Esses foram os desafios que tentamos enfrentar na implantação de uma clínica psicanalítica para autistas na Universidade Federal de São João del-Rei (UFSJ). Nosso objetivo é apresentar não somente os fundamentos teórico-clínicos dessa práxis, mas também o modo como pudemos, sem abandonar os princípios da psicanálise, inovar no atendimento e na formação de novos profissionais.

\section{Contextualização}

A capa da revista do Conselho Regional de Psicologia de Minas Gerais (CRP-MG) do mês de abril de 2019 faz uma chamada interessante: "Múltiplas abordagens dapsicologia sobre oautismo". Interessados no campo dos autismos, fomos levados por essa chamada a buscar nas páginas da revista mais esclarecimentos sobre os autismos, os tratamentos e seus modos de fazer na relação com o Outro ${ }^{1}$. No entanto, notamos que na apresentação das instituições e espaços de atendimento para crianças autistas que aparecem na reportagem, menciona-se somente uma instituição de Minas Gerais que orienta seus trabalhos a partir da psicanálise: o espaço Conviver, em Varginha, que teve destaque merecido pelo trabalho que realizam. No entanto, é importante ressaltarmos que, em Minas Gerais (e no Brasil em geral e outros países²), há várias outras instituições que trabalham com psicanálise e autismo e não foram mencionadas na referida publicação. Destacarmos esse fato é essencial a fim de

\footnotetext{
${ }^{1}$ Na Orientação Lacaniana, o Outro é nomeado como o campo simbólico onde o sujeito é introduzido por meio da linguagem. Essa inserção na ordem simbólica favorecerá à criança tornar-se um ser que habita a linguagem. Por outro lado, o outro com minúscula, em psicanálise, designa a outra pessoa, que participa da vida da criança, como, por exemplo, a mãe.

${ }^{2}$ Podemos citar vários projetos em todo o Brasil, como o Lugar de Vida e a Derdic em São Paulo; os diversos núcleos do Projeto Pipa e Rabiola; o projeto Circulando no Rio de Janeiro; Antenne 110 na França; e Le Courtil na Bélgica. No corpo do texto nos remetemos
} 
indicarmos, para autores, pesquisadores e também pais e professores que se dedicam ao tema, que a produção em psicanálise no trabalho com autismos é profícua, seja academicamente, seja clinicamente. Desse modo, viemos aqui, nesta seção, identificá-las e, de certo modo, parabenizá-las pelo empenho em tal empreitada na clínica com crianças autistas. Citamos algumas de nosso conhecimento: a Clínica-Escola da Pontifícia Universidade Católica de Minas Gerais (PUC Minas), em Coração Eucarístico, Belo Horizonte; o Centro de Atendimento e Inclusão Social (CAIS), em Contagem; o Centro Psíquico da Adolescência e Infância (CepaiFhemig), em Belo Horizonte; o ambulatório da Faculdade de Ciências Médicas de Minas Gerais; a Equipe Complementar Centro Sul da Prefeitura Municipal de Belo Horizonte; e a Clínica-Escola da Universidade Federal de Uberlândia (UFU). Além disso, apresentaremos, neste artigo, o relato da implantação de mais uma clínica para crianças autistas na UFSJ, também no estado de Minas Gerais.

Damos esse destaque para pôr à prova a importância da clínica psicanalítica dos autismos em tempos de massificação do tratamento, que pretende retirar a psicanálise do campo de práticas possíveis de atendimento em políticas públicas de saúde mental e no tratamento do autismo mais especificamente. A Batalha do Autismo, como nos diz Laurent (2014), é empreendida para que haja espaço para diversidade de abordagens, contrariamente à imposição de modo único para a consideração do autismo no campo das políticas públicas de atendimento à saúde mental infantil. Todavia, na mídia, nas redes sociais e em editais ${ }^{3}$, verificamos a imposição de uma única abordagem de tratamento, que utiliza protocolos e classificações universalizantes do sujeito, em detrimento de uma prática do singular. Por isso, neste artigo, por meio de um investimento e esforço constantes, e, sobretudo, amparados pelo desejo pela psicanálise, buscamos apresentar que, além dessas instituições que trabalham com crianças autistas sob a práxis psicanalítica em Minas, há um novo lugar para o tratamento do autismo em Minas Gerais. Esse lugar situa-se entre os muros da UFSJ, que abriga, desde o ano de 2016, o projeto de uma clínica para o tratamento de crianças autistas pela psicanálise. Objetiva-se mostrar como se fundamenta essa clínica, como ela se iniciou, seu funcionamento, sua práxis na instituição e como se dá o tratamento do autismo no Serviço de Psicologia na Universidade.

\section{Psicanálise em instituições}

A proposta de implantar uma clínica de atendimento a crianças autistas no âmbito de uma instituição universitária se dirige ao encontro da possibilidade de construção de um método clínico ancorado na psicanálise, que dê conta da singularidade dos sujeitos autistas. Dessa forma, uma questão emerge: como criar uma instituição a partir da psicanálise? Como nos diz Stevens (2007), não há uma receita, um modelo: "é a clínica que decide por nós, tanto pela idade dos jovens que recebemos quanto pelos problemas clínicos apresentados por eles" (p. 78). Entretanto, ele interroga: "Como passar da psicanálise pura para a psicanálise aplicada sem que isso comprometa a psicanálise?" (Stevens, 2007, p. 76). Esse questionamento nos relembra a observação feita por Freud (1919/1980) em seu texto "Linhas de Progresso na Terapia Psicanalítica", que tanto vislumbra a possibilidade de entrada da psicanálise nas instituições e sua aplicação em larga escala, como também expressa sua preocupação com uma situação que "nos force a fundir o ouro puro da análise com o cobre da sugestão direta" (p. 211). Essa preocupação freudiana com uma possível degradação da psicanálise ao ser inserida no campo institucional é também nossa. Todavia, tal como reiterado por Freud em 1914, na "História do Movimento Psicanalítico”, nosso objetivo, com a implantação dessa clínica, é seguir definindo e reafirmando o que é a prática psicanalítica em oposição àquilo que ela não é. Nosso intento com a implantação de uma clínica em uma instituição universitária foi uma aposta na possibilidade de tratamento do autismo pela psicanálise. Isto é, o que deve estar em jogo com a entrada da psicanálise na instituição é a viabilidade de se iniciar um tratamento. Faz-se importante, sobretudo, pensar a especificidade da clínica psicanalítica na instituição.

apenas a Minas Gerais devido ao fato de a revista do CRP-MG ter citado apenas uma instituição, demonstrando que mesmo em uma escala menor, os diversos serviços psicanalíticos ainda são desconhecidos, apesar de serem muitos.

${ }^{3}$ No Diário Oficial do Estado de São Paulo de 4 de setembro de 2012, foi publicado um Edital de Convocação Pública chamando para o credenciamento de Instituições Especializadas em Atendimento a Pacientes com Transtorno do Espectro Autista (TEA), para eventual celebração de contrato ou convênio e com a exigência de que o método utilizado fosse Cognitivo Comportamental validado na literatura científica 
Quando a instituição é uma Universidade Federal, devemos levar em consideração a perspectiva de formação profissional, como também a necessidade de fazermos a extensão universitária e pesquisas, que visam a pensar a especificidade da clínica nesses serviços, para melhor formalizar nossa práxis. Acreditamos ser necessário pensar essa especificidade uma vez que, por um lado, se houve avanços no setor psicossocial nos serviços - afirmação da autonomia e cidadania do usuário do serviço -, por outro lado, houve um certo desmerecimento da clínica e até mesmo afirmação de oposição entre a reabilitação e a clínica (Kyrillos Neto \& Calazans, 2012). A esse equívoco seguiu-se outra contenda que, a nosso ver, também é falsa: entre a psicanálise e a Reforma Psiquiátrica. A contenda teve partidários dos dois lados. Do lado da reabilitação, houve a associação entre modelo asilar, clínica e psicanálise. Do lado da psicanálise, houve a associação da reabilitação com adaptação e recusa ao sujeito. Equívocos que não auxiliaram em nada a formulação de estratégias adequadas para a assistência, como demonstram Onocko Campos (2001), Antonio Quinet (2006) e Kyrillos Neto e Calazans (2012).

O desafio se amplia quando pensamos que a inserção da psicanálise em instituições públicas foi assunto controverso durante um bom tempo no âmbito analítico, pois havia a prerrogativa de que a psicanálise era uma práxis que trazia a especificidade de estar inserida somente no espaço privado dos consultórios. Ademais, a questão da técnica implicava uma dificuldade, principalmente pelo estabelecimento da transferência ${ }^{4}$. Esta, concebida no dispositivo analítico como a pedra angular da psicanálise, não poderia ser estabelecida em uma instituição. O que se deve considerar, muito mais do que se pensar que a psicanálise está extramuros do consultório, do setting e da estandardização, é a "exigência ética" de que a psicanálise na instituição seja psicanálise (Naveau, 2007, p. 9). E, como veremos na seção Métodos, a questão da transferência nos casos de autismo em instituição não foi descuidada por nós.

\section{A não idiotia teórica e institucional da psicanálise}

Phillipe Julien (2002) disse que a psicanálise não conhece a idiotia; ou seja, ela não conversa sozinha com um dialeto somente seu, mas sempre está aberta ao debate. A psicanálise, desde seu surgimento com Sigmund Freud em 1900, sempre se destacou pela sua precisão clínica e pela reformulação à qual ela obrigou a psicopatologia, em um debate enriquecedor para as duas disciplinas. A fim de situarmos um exemplo no campo da psicopatologia infantil, podemos designar o surgimento da noção de autismo como derivada do trabalho de Freud sobre o autoerotismo (1905/1980), que permitiu o estabelecimento de um sintoma secundário na esquizofrenia e a formulação, na década de 1940, do autismo como entidade clínica diferenciada de outras psicopatologias (Bercherie, 1992).

Se a psicanálise, por um lado, tem esse grande impacto sobre a clínica e sobre a psicopatologia, não podemos esquecer que ela jamais se furtou ao trabalho com outras propostas a ponto de incorporar ao seu arsenal clínico e conceitual noções surgidas de autores que se colocavam em posição completamente distinta da do psicanalista. Como exemplo, citamos a noção de automatismo mental, surgida na pena do organicista Clérambault e adotada por Jacques Lacan, como um dos indícios a ser procurado em uma entrevista preliminar (Harari, 2006).

A psicanálise, por sua vez, não ficou restrita à reformulação da clínica e da psicopatologia do adulto. No que tange à infância, sua contribuição foi maior: ela foi decisiva para a separação da clínica infantil da clínica do adulto. Bercherie (1992) aponta como a psicanálise permitiu que se desse uma especificidade à clínica da criança, fazendo com que ela deixasse de ser um espelhamento da clínica do adulto e se constituísse em uma clínica com quadros próprios. Se tomarmos os conceitos de psicose infantil e autismo, vemos como a psicanálise foi pioneira com os trabalhos de Anna Freud e Melanie Klein e, depois, com os trabalhos de Donald Meltzer e Francis Tustin para a clínica da criança, que necessita de tratamento intensivo (Letra Freudiana, 1995).

No que se refere à orientação lacaniana, variadas foram as contribuições pioneiras na clínica com crianças, principalmente no contexto institucional. Entre elas, podemos destacar: a iniciativa do psiquiatra catalão François Tosquelles (Ruiz, Athayde, Nogueira Filho, Zambroni-de-Souza, \& Athayde, 1992), que, durante a Segunda Guerra Mundial, trabalhou orientado

\footnotetext{
${ }^{4}$ Transferência é um termo introduzido por Freud (1912/1980) para designar um processo essencial e constitutivo do tratamento psicanalítico, que se distingue de todas as outras psicoterapias pela presença da transferência.
} 
pela psicanálise em um hospital para psicóticos no sul da França; Françoise Dolto (2010) e Maud Mannoni (1981), a partir da fundação da Escola Experimental de Bonneuil-sur-Marne em 1969; e Rosine e Robert Lefort (1984), até resultar, em tempos atuais, nos trabalhos de Antonio di Ciaccia (2007), Virginio Baio (2007), Alexandre Stevens (2007) e Alfredo Zenoni (2000).

Podemos contar com os trabalhos brasileiros de Jeanne Marie de Leers Costa Ribeiro (2005), Angela Vorcaro (2004), Angela Vorcaro, Aline Vilela e Franciele Oliveira (2012) e Maria Cristina Kupfer e Fernanda Noia Pinto (2010), além do estudo multicêntrico para identificação de riscos de desenvolvimento infantil desenvolvido por Maria Cristina Kupfer et al. (2009).

Nossa aposta na implantação de uma clínica para crianças autistas na universidade é, portanto, fundamentada na história, na aplicação de seus fundamentos e na reformulação de seus métodos em instituições. No Brasil, essa questão se intensifica a partir da Reforma Psiquiátrica, que conta com quase 30 anos desde seu início, e percebemos, assim, um interesse crescente na busca de novos referenciais, que substituíram as formas antigas de segregação por novos modos de se trabalhar na assistência à saúde mental. Primeiramente, vimos um maior envolvimento no campo da saúde mental dos adultos e a manutenção da criança e do adolescente em um alcance menor de assistência (Guerra, 2003). Porém, vemos um investimento maior por meio de políticas públicas, que colocam em destaque a criança e o adolescente em seu sofrimento psíquico. A reformulação da assistência pública à saúde mental, como nos diz Guerra (2003), "vem marcada pelo atravessamento da clínica, demarcando uma proposta que articula subjetividade e dimensão política na organização da assistência" (p. 172). A psicanálise participa dessa articulação gerando a tensão já conhecida entre um campo assistencial do "para todos" e a clínica do um a um. Desse modo, faz-se necessário pensar em como a clínica se configura na instituição e, também, como estabelecer métodos de atendimento que não deixem de considerar e implicar o sujeito do sofrimento psíquico. Para isso, a construção de um projeto terapêutico para uma clínica de apoio à criança autista foi nosso objetivo principal como metodologia de trabalho, assim como a construção do caso clínico. Porém, antes de articular essas duas faces de nosso método de atendimento de autistas, é forçoso dizer sobre a importância da transferência no tratamento psicanalítico.

\section{Clínica sob transferência}

Freud, em 1905, ou seja, cinco anos após o lançamento de "A Interpretação dos Sonhos" (1900/1980), escrevendo a propósito de sua experiência como criador de um método de tratamento do sofrimento subjetivo - a psicanálise -, expunha dois aspectos que deve-se considerar quando estamos às voltas com o tratamento não somente do autismo, como também de psicoses e de neuroses graves: o primeiro aspecto é a lembrança de Freud (1905/1980, p. 67) de que, muitas vezes, seus colegas médicos mandavam a ele casos refratários a tratamentos, mas com a expectativa de que Freud os hipnotizasse. Por isso, ele explica que a psicanálise não é um tratamento que pretenda aplicar alguma coisa ao paciente ou introduzir algo novo, mas retirar, por meio do trabalho, algo com o qual o sujeito fique embaraçado e produza sintomas. Ainda nessa linha, Freud (1905/1980, p. 70) lembra que seu método terapêutico foi elaborado e testado em casos graves, que haviam tentado outros métodos sem sucesso e viviam há anos em instituições. Ou seja, a psicanálise surge, justamente, dos casos considerados difíceis. Por isso mesmo, não devemos recuar frente a nenhum caso com o qual nos defrontemos em nossa práxis.

O segundo aspecto é uma variação do primeiro: se a psicanálise surge de casos refratários a outros tratamentos, ainda assim haveria casos que Freud (1905/1980), naquele momento, considerava contraindicados para o tratamento psicanalítico: degeneração neuropática (p. 71); pessoas que se submetem a tratamento por imposição de parentes (p. 71); psicoses, estado de confusão e de profunda melancolia (p. 72); pessoas próximas ou acima de 50 anos (p. 72); casos de manifestações ameaçadoras como anorexias histéricas (p. 72). Então, Freud (1905/1980), em relação às psicoses, confusão mental e à melancolia, vai dizer algo que pode ser extensivo às outras contraindicações (e que a história do movimento psicanalítico confirmou): "Não descarto absolutamente que com uma modificação adequada do procedimento se possa superar essa contraindicação e, assim, iniciar uma psicoterapia das psicoses" (p. 72).

Nessa passagem, vemos que Freud não recua frente aos casos graves - é por meio deles que faz 
nascer a psicanálise como tratamento originariamente das neuroses - e aponta, como bom epistemólogo que é, que, ao se deparar com casos que seriam a princípio contraindicados, é necessária uma modificação no procedimento. Essa experiência de modificação de procedimento de tratamento está em jogo em qualquer tratamento, sobretudo no caso de tratamento de crianças autistas. Ou seja, devemos estar atentos à tensão entre a lógica da psicanálise, que estabelece alguns parâmetros para um tratamento ser considerado psicanalítico, e o real dos casos que implicam essas modificações no procedimento, mas não seu abandono, como especificado na questão da prática entre vários na seção anterior.

Dessa maneira, retomamos, aqui, a questão: como pensar o tratamento psicanalítico nos casos de autismo? Como aponta Maria Rita Carneiro Ribeiro (2001), essa questão comporta uma série de invenções de acordo com a experiência do encontro de cada clínico com as crianças. Ferreira e Vorcaro (2017) confirmam essa proposição a partir de pesquisa sobre os tipos de tratamento realizados pelos psicanalistas. Nela, encontramos uma diversidade de tratamentos exatamente tão extensa quanto o número de analistas. No entanto, como se trata de pensar um tratamento psicanalítico, temos que partir da noção de transferência como motor do tratamento.

Como psicanalistas, temos que partir de nossa estratégia básica - ou do que Freud chamava de procedimento - de tratamento estabelecido por Freud, que é a transferência. De acordo com Jacques-Alain Miller (1994), não há tratamento psicanalítico senão sob transferência, porém, resta-nos a mesma questão colocada por Lacan a propósito das psicoses: usar a mesma estratégia do tratamento das neuroses para o tratamento das psicoses é o mesmo que "esfalfar-se nos remos quando o barco está encalhado na areia" (Lacan, 1959/1998, p. 590). Se nos dispomos a usar a transferência é porque por meio dela podemos encontrar o sujeito e permitir que suas respostas sintomáticas possam tomar outra direção no tratamento da angústia e na moderação do gozo. Desse modo, assim como no caso das psicoses, nos casos de autismo precisamos não nos perdermos em estratégias que não comportem uma invenção a partir dos sintomas das crianças autistas.
Um aspecto nos permite aproximar e afastar, então, a questão da transferência nos casos de autismo tratados em instituições com a questão das psicoses: por um lado, mesmo que identifiquemos, como Maleval (2014), uma estrutura autística distinta da estrutura psicótica, por outro lado, tanto nas psicoses como nos autismos estamos às voltas com a foraclusão ${ }^{5}$ e seus efeitos, especialmente a não extração do objeto. Os resultados dessa não extração do objeto são diferentes nas duas estruturas: em uma, comporta uma possibilidade de tratamento delirante e, na outra, comporta uma total aversão a qualquer investida do Outro desde a mais tenra infância. Isto é, nos dois casos, a aproximação do Outro é maciça demais sem a falta que caracteriza o circuito do desejo neurótico, mas com apresentações diferentes.

Se as aproximações do Outro são maciças, causando angústia ao sujeito no autismo - o que de certo modo explica que os dois sintomas patognômicos do autismo desde Kanner sejam o desejo de solidão e o de imutabilidade -, na questão transferencial, tanto nas psicoses como nos autismos, trata-se de evitar que a relação transferencial se torne maciça também. Como já demonstrava Kanner, falar com os autistas sem se endereçar diretamente a eles, falar com eles modulando vozes, muitas vezes cantarolando, seriam modos de obter alguma resposta deles. Na interpretação psicanalítica, trata-se de evitar que uma ação se torne maciça a ponto de angustiar a criança, desencadeando uma crise de choro, gritos, automutilações etc. Afinal, como nos lembra com pertinência Maleval (2017):

Certamente o dispositivo analítico estrito praticamente não convém às crianças autistas-são raras as que puderam nele investir e tirar proveito. Contudo, Lacan considerava que havia certamente algo a dizer a elas, com a condição, precisa ele, de que delas se ocupem de modo adequado, para que elas possam escutar. Assim, convidava o clínico a acatar as invenções do sujeito autista mais do que lhes prescrever métodos formatados (p. 375).

Ora, é diante desse cenário que colocamos a questão do tratamento dentro das condições iniciais de nosso trabalho: um serviço ambulatorial em um Serviço de Psicologia Aplicada de uma Universidade

\footnotetext{
${ }^{5}$ Conceito forjado por Jacques Lacan para designar um mecanismo de defesa específico da psicose, através do qual se produz a rejeição a um significante fundamental para a introdução do sujeito no universo simbólico (Roudinesco \& Plon, 1994).
} 
Federal. Como vimos, a partir do desenvolvimento da psicanálise lacaniana, a prática entre vários constitui a possibilidade de tratamento a partir de um "desejo distinto da vontade de educá-lo, de dominá-lo ou de inseri-lo no status quo das demandas da sociedade" (Barroso, 2014, p. 346) e, assim, respeitar as invenções que serão possíveis "para ela não sair do autismo, mas sim do seu mundo imutável e assegurado, o que lhe abre um acesso à vida social" (Maleval, 2017, p. 378). É nesse sentido que Éric Laurent (2014, p. 61), assevera, a partir do comentário de um caso clínico, o que seria a transferência no autismo: a transferência é poder dizer algo a alguém e ele ouvir, uma vez que se trata, aí, de sair do lugar de alguém, que exige o gozo de alguém:

A transferência se mostra no fato de que uma criança autista, tão grave nessa idade - se alguém lhe fala sobre seu cocô (como Cristina o fez) possa ouvir o que o analista tem a lhe dizer e, depois de uma sessão assim, não fazer mais cocô na escola, como antes. É incrível, e de coisas como essas não é, jamais, um comportamentalismo que pode dar conta.

Ora, se é preciso respeitar as ilhas de competência dos autistas, seus objetos singulares para além de um ordenamento a partir do mundo e o discurso dos adultos para que não sejamos invasivos em nossa práxis e, assim, permitir uma certa errância para não exigir diretamente uma posição de enunciação, é necessário, então, o que parece, de acordo com a pesquisa de Ferreira e Vorcaro (2017), uma constante entre as várias práticas lacanianas: que a transferência seja o que elas chamam de transferência diluída. "Diante da absoluta dificuldade do sujeito com o Outro, a transferência diluída entre vários poderia apaziguar o sujeito dos efeitos aterradores do Outro invasivo" (p. 101).

A partir dessas advertências, optamos, em termos de tratamento, por duas invenções, salvo melhor juízo, para efetuar o tratamento das crianças autistas em psicanálise. A primeira foi introduzir, em trabalho ambulatorial, o tratamento com dois estagiários dos cursos de graduação e pós-graduação em psicologia, e não somente com um, a fim de implementar a diluição do Outro na transferência. A segunda deriva da grande literatura sobre os pais de autistas, segundo a qual o significante autismo se torna, quando da informação do diagnóstico, inteiramente maciço também. Desse modo, acreditamos que seria importante criar uma outra equipe, distinta tanto em termos de membros como de supervisores, para atendimento dos familiares, a fim de que possamos diminuir o fator libidinal carregado no significante autismo e para que essa criança não seja um condensador de gozo da família, fixando-a nesse lugar imutável. A questão do tratamento dos familiares, iremos explorar em outro momento.

\section{Métodos}

\section{Projeto terapêutico: prática entre vários}

Uma questão que se impõe quando se trata de se pensar um dispositivo clínico é: como fazer? Uma resposta refere-se à modalidade de trabalho proposta por Miller (1994) de "uma prática entre vários" e elevada por Antonio di Ciaccia (2007) ao nível de método. Essa prática serve-se do múltiplo, junto aos membros da equipe, para favorecer certa destituição subjetiva no trabalho em instituição. A presença de muitos no trabalho com as crianças tem um valor importante, pois demarca que não haveria um saber em uma única pessoa. Dessa maneira, há uma pluralização da transferência, o que ameniza os efeitos sintomáticos persecutórios dos sujeitos (Kusnierek, 2007).

Esse dispositivo é uma das modalidades da psicanálise aplicada e exige, por parte dos analistas, uma invenção no trabalho com o outro. Essa é uma prática na instituição em que todos, em posição de analistas, estão implicados. É uma prática, diz-nos Kusnierek (2007), em que subjaz um método, e não um modelo; portanto, replicar esse método como um modelo nas instituições se distancia, sobremaneira, da especificidade do método. A prática entre vários tem a especificidade de não contar com um adulto especialista, mesmo que seja psicanalista; o que essa prática apresenta e concerne é que quem se ocupa da criança é um adulto, que se sustenta por sua presença e por seu ato para o trabalho com autistas e psicóticos. Contudo, o trabalho na instituição por meio da prática entre vários é um método que agrega todas as intervenções realizadas por todas as pessoas que trabalham com a criança na instituição. Sendo um trabalho feito por muitos, não há um único a saber fazer. Todavia, cada um é responsável por seu ato (Kusnierek, 2007). 
Em um texto intitulado "Inventar a Psicanálise na Instituição”, Antonio di Ciaccia (2007) revela que, no momento em que se viu diante da situação de ter que organizar uma instituição - Antenne 110 para crianças autistas e psicóticas, em 1974, o que o movia a tal intento era "provar ou refutar a afirmação de Lacan, segundo a qual a criança autista também está na linguagem" (p. 69). Do mesmo modo, a afirmação de que a criança autista está na linguagem, mas não barrada pelo significante, e sim como um condensador de gozo, permite fazer uma aposta em um dispositivo que contemple essas crianças em uma instituição (Ciaccia, 2007).

Para o projeto de clínica em instituição, Ciaccia (2007) propõe três eixos, que funcionam como norteadores de trabalho. O primeiro se refere à reunião dos membros da equipe, lugar onde a fala é colocada para fazer a separação entre o saber adquirido dos adultos e o lugar subjetivo da criança. O segundo eixo proposto por ele refere-se à função do responsável terapêutico, que pode ser exercida "por qualquer um, mas não por um qualquer” (Ciaccia, 2007, p. 73). O responsável técnico deve permitir a cada membro da equipe atuar para confirmar "a justeza do axioma de Lacan, segundo a qual a criança autista também está na linguagem" (Ciaccia, 2007, p. 73).E, finalmente, o terceiro eixo está relacionado à referência teórica e clínica ancorada na orientação lacaniana.

Um pouco mais tarde, em 1982, Alexandre Stevens criou o Le Courtil sobre as bases de Antenne 110, o que não quer dizer que seja um outro modelo. Nesse ponto, Stevens (2007) afirma que "não há modelo nesse domínio, é a clínica que decide por pós, tanto pela idade dos jovens que recebemos quanto pelos problemas clínicos apresentados por eles" (p. 78). Stevens, também, propôs eixos, que serviram como orientadores para a criação do Le Courtil. São quatro no total: o primeiro é a desespecialização, que se refere, como nos diz o autor, aos processos de desindentificação. Como exemplo, ele cita a nomeação dada ao Le Courtil enquanto uma instituição para crianças autistas e neuróticas graves. Dessa maneira, a desespecialização visa "a evitar a identificação monossintomática: autista, toxicômano, anoréxico..." (Stevens, 2007, p. 79). Ainda no primeiro eixo proposto, a desespecialização refere-se ao trabalho de cada um. Aqui, aplica-se a prática entre vários, cuja importância atribui-se à distinção em relação à prática pluridisciplinar. Nessa última, cada profissional trabalha de acordo com sua especialidade. Na prática entre vários, a desespecialização do trabalho de cada um ocorre por meio da construção do caso, que atravessa todos os pontos de vista dos especialistas. Há, como resultado dessa prática, reuniões clínicas, nas quais se buscam invenções do sujeito, e não reuniões de síntese: "Tudo na instituição é articulado a partir dessa clínica do caso" (Stevens, 2007, p. 80).

O segundo eixo concerne à formação, pois é preciso que o desejo pela psicanálise seja um ponto de sustentação para o trabalho na instituição; uma formação que não passe, necessariamente, pelas escolas de formação em psicanálise, mas que permita a transferência pela psicanálise.

O terceiro eixo faz uma exigência à permanência da invenção nessas instituições. As invenções concernem ao fato de os profissionais estarem "prontos para ouvir a surpresa”, como nos diz Stevens (2007, p. 81). Essas surpresas, continua ele, são produzidas por cada sujeito, cabendo ao analista estar na posição de responder a essas invenções de cada um com um não saber, para que elas possam ter um achado particular como resposta.

Como quarto e último eixo, temos a transmissão. A reunião clínica semanal é o lugar onde a transmissão se apresenta, pois essa reunião serve para colocar em destaque as intervenções realizadas, caso a caso, e dimensioná-las de acordo com a resposta apresentada por cada criança. As decisões, no que diz respeito ao tratamento, serão realizadas nessa reunião (Stevens, 2007). Desse modo, ancorados na práxis psicanalítica e tomados pelo desejo da psicanálise, dirigimo-nos rumo à construção de um projeto terapêutico, que possibilitou a realização de uma clínica com crianças autistas no interior de uma instituição universitária, mas sempre respeitando a condição única para que se possa dizer que um trabalho aconteça de modo psicanalítico: sob transferência.

\section{Clínica com crianças autistas na universidade: a construção do caso clínico}

Ao pensarmos a implantação de uma clínica que busca atender a crianças autistas, nosso objetivo se dirigiu à construção de um método clínico que dê conta da particularidade desses sujeitos. Todavia, não há caminho pronto. Ele é uma construção e, como tal, nos convoca, incessantemente, à criação e à invenção. 
Amparados nos fundamentos da clínica psicanalítica, nosso objetivo inicial na construção dessa clínica foi delimitar suas especificidades no tratamento do autismo. Para tanto, pensamos na particularidade dessa criança quanto à transferência, à dificuldade do contato com o Outro e a seu modo singular de fazer uso da linguagem. Além disso, sua posição na família e sua lógica de funcionamento nos são caras para apreendermos seu modo de estar no mundo.

Autores como Antonio di Ciaccia (2007) e Virginio Baio (2007), com seus modos de fazer em Antenne 110 e Le Courtil, respectivamente, nos convocaram a uma maneira não absolutamente original, mas essencialmente particular na construção do método clínico. Utilizamos, em nossa prática clínica com crianças autistas na universidade, o que a psicanálise chama de construção do caso clínico. A partir dela, os motores do método clínico que nos guiam para a construção do caso são: a reunião dos membros da equipe, o lugar de um não saber do analista sobre o caso, a posição do analista na transferência e, finalmente, o desejo pela psicanálise.

A construção do caso clínico tem sido, no Brasil, um modo privilegiado de inserção da psicanálise nas instituições de saúde mental. Autores como Viganò (2010), Alkmim (2003), Figueiredo (2004), Vorcaro (2004) e Vorcaro, Vilela e Oliveira (2012) têm apostado na construção do caso clínico como algo que seria específico da psicanálise em sua inserção nas instituições de saúde mental, uma vez que tal proposta se fundamenta no particular do sujeito.

Viganò (1999), fazendo uma etimologia das palavras "caso" e "clínica", destaca que "caso vem do latim cadere, cair para baixo, ir para fora de uma regulação simbólica; encontro direto com o real, com aquilo que não é dizível, portanto impossível de ser suportado" (p. 40). Além disso, a palavra clínica, continua ele, vem do grego kline e quer dizer leito: "A clínica é ensinamento que se faz no leito, com a presença do sujeito. É um ensino que não é teórico, mas que se dá a partir do particular; não é a partir do universal do saber, mas do particular do sujeito" (p. 40). No entanto, quando falamos de construção do caso clínico, deve-se lembrar que construção, como nos diz Figueiredo (2004), é diferente de interpretação, porque esta é pontual, visa a um sentido, enquanto a construção "é um arranjo dos elementos do discurso visando a uma conduta” (p. 78). A construção tem como objetivo partilhar elementos de cada caso em um trabalho conjunto, sendo, assim, um método clínico de maior alcance. Em resumo, diz-nos Figueiredo (2004), "a construção do caso clínico em psicanálise é o (re)arranjo dos elementos do discurso do sujeito que 'caem', se depositam com base em nossa inclinação para colhê-los, não ao pé do leito, mas ao pé da letra" (p. 79).

Alkmim (2003) também dá sua contribuição ao dizer que a construção do caso clínico como forma de sustentar o discurso analítico na instituição vai de encontro a uma clínica da instituição como exceção. Essa clínica responde de um lugar, de maneira única, às demandas do sujeito. Essa clínica parte de um não saber do sujeito, o que coloca todos os profissionais da equipe em uma posição de igualdade no que se refere à ignorância do caso. Isso significa operar com o saber trazido pelo paciente, e não sobre o paciente. Outrossom, continua Alkmim (2003), uma construção do caso clínico permite trabalhar com a provisoriedade do caso, subvertendo o que permanece estanque em práticas que utilizam a classificação e nomeação do sujeito.

Ainda no que concerne à construção do caso clínico, Alfredo Zenoni (2000) recomenda que, no lugar de analistas, devemos ser também "aprendizes da clínica”, retirando das elaborações do sujeito os critérios para a condução do tratamento. Figueiredo (2004) aponta, quanto a essa expressão, para a necessidade de que a equipe que conduz o caso formule "boas questões" e, do mesmo modo, verifique os "efeitos de suas intervenções”, para, assim, tomar novas decisões ou dar nova direção a um determinado caso a partir dos efeitos sintomáticos apresentados pelo sujeito. Isso porque qualquer resposta do sujeito ao tratamento, mesmo que esta emerja no desencadeamento de uma crise, é vista, na perspectiva da construção do caso, como possibilidade de uma invenção particular do sujeito.

A partir dessas considerações, nossa proposição na implantação da clínica do autismo é construir um método que se ancora no caso clínico e que se guia pela particularidade dos sujeitos nessa clínica. Nosso ponto de inserção e construção do caso no tratamento com crianças autistas se dá por meio do relato dos estagiários que atendem a criança. Esses relatos são realizados em supervisão coletiva, em que o estagiário apresenta o caso e considerações sobre ele são proferidas não só pelo supervisor, mas também pelos alunos e, do mesmo modo, 
não somente pelos que atendem a criança, mas por todos que participam do trabalho na clínica. A partir de então, as intervenções são construídas em conjunto com todo o grupo de estagiários. Há um fazer nessa clínica, que se ancora na construção das possibilidades a que o sujeito autista recorre, de modo singular, ao longo do tratamento. Esse recurso singular utilizado pela criança é um ponto orientador para o trabalho de construção do caso, pois é a partir desse modo singular de se manifestar que buscamos a lógica de seu funcionamento psíquico.

Não podemos perder de vista o fato de que esse modo singular pode, muitas vezes, divergir ou mesmo contrariar a estratégia genérica, que a política preconiza como ideal comum a todos, como Freud já havia identificado em "Mal-estar na civilização" (1929/1980). É de suma importância deixarmos um espaço aberto para a emergência de algo que não consta no projeto da equipe. Só assim será possível algo da verdade subjetiva de cada sujeito advenha ali, onde só há um saber instituído, previamente, à revelia do sujeito.

Estabelecido que os atendimentos se amparam no caso clínico, é função do analista outro ponto que foi considerado. Uma clínica para pacientes autistas requer uma prática feita por muitos. As equipes multiprofissionais são a realidade dessa prática, porque há uma heterogeneidade de atos entre todos e, amparando esses atos, muitos saberes para sustentá-los. Os riscos dos efeitos imaginários de grupo, referidos ao poder, à rivalidade e ao narcisismo das pequenas diferenças (Freud, 1921/1980), podem ser enfrentados ou dissipados - ou não - conforme a posição da equipe em relação ao saber. Querer saber e se alimentar do poder acirram os efeitos imaginários e animam a tentativa de fazer Um, Um do Mestre. Por outro lado, sustentar a posição de Um não saber central, Um do vazio, do que sabe não saber (Baio, 2007; Ciaccia, 2007), pode, ao contrário, deslocar o desejo de mestria para uma posição esvaziada, furada, que oferece ao sujeito espaços para que ele possa produzir uma questão ou mesmo uma resposta, um saber sobre si.

$\mathrm{O}$ trabalho entre vários permite esvaziar esse discurso por cada um ser destituído desse saber uníssono, que tenta adequar a criança na instituição pelo discurso do mestre. Assim, a diferença serve para fazer série. Isto é, cada membro da equipe é mais um entre vários. Essa corrente, criada pela diferença de estilo nas intervenções de cada profissional, torna-se imprescindível para promover uma mudança subjetiva no sujeito autista, pois o profissional se apresenta como barrado, descontínuo e heterogêneo (Kupfer \& Pinto, 2010).

Uma prática por muitos tem, pois, por função, inicialmente, tratar os efeitos imaginários nefastos e improdutivos próprios a todo coletivo. Além disso, implica em presentificar um Outro cujo saber e cujo poder são esvaziados para o sujeito, permitindo que se criem espaços vazios nos quais o sujeito possa produzir respostas, possa construir saídas (Guerra, 2003, p. 179).

A partir dessa prática, a presença de dois terapeutas $^{6}$ nos atendimentos foi uma estratégia clínica utilizada, que permitiu a presença de um Outro menos invasivo. Nas primeiras sessões, uma professora supervisora e um aluno iniciam o trabalho. A presença da professora toma o primeiro plano na cena analítica, enquanto o estagiário, futuro multiplicador, fica em um canto da sala fazendo as anotações do que observa no atendimento. O estagiário não intervém, a não ser que a criança solicite, o que não é incomum, mas não ocorre sistematicamente. Na maioria das vezes, a posição do estagiário no segundo plano é a de "resto", o que se esclarece com o fato de a criança não o solicitar, nem mesmo quando o estagiário se manifesta, como se ele estivesse ausente. Desse modo, a presença de dois terapeutas no setting nos leva a considerar que, na relação transferencial, o olhar e a voz, signos da presença do Outro, ficam menos invasivos do que em um atendimento individualizado.

Entretanto, no momento em que o segundo terapeuta começa a ser visto pela criança e por ela convocado a se inserir no trabalho, há uma mudança no setting, suportável para essa criança. O professor, primeiro da cena, se retira para que o estagiário segundo - entre como primeiro dando oportunidade para que outro estagiário entre na cena do atendimento. Dessa forma, o segundo estagiário, ao se deslocar para o lugar do primeiro terapeuta, se torna um multiplicador dessa clínica em que outros estagiários poderão se beneficiar dessa prática.

${ }^{6}$ A presença de dois terapeutas se inspira em um modelo de atendimento denominado Atendimento Psicoterapêutico Conjunto Pais-Crianças, desenvolvido na Clínica de Psicologia da Universidade Federal de Uberlândia (UFU) com a supervisão do professor Dr. João Luiz Leitão Paravidini e da psicóloga Maria Hélvia Cristine Castro Silva Perfeito (Paravidini, Próchno, Perfeito, \& Chaves, 2009). 
Ainda no que concerne ao analista e sua posição na clínica, Alexandre Stevens (2007) destaca que a função do analista não é interpretar incessantemente, mas essencialmente. Estamos no lugar daquele que está pronto para escutar a surpresa, para escutar o momento de invenção, invenção particular de cada sujeito frente àquilo que ele não consegue organizar. Uma invenção que funciona como um ponto de basta sobre aquilo que da função paterna não operou para o sujeito. $\mathrm{O}$ analista participa nesse processo não para produzir o significante que o ajudará a regrar seu mundo subjetivo, mas para testemunhar seu achado (Stevens, 2007). Portanto, a função do psicanalista nessa clínica aplicada à terapêutica é "estar pronto a acolher a surpresa que valerá como saída para o sujeito, isto é, como palavra justa para dizer o real com o qual ele está confrontado" (Stevens, 2007, p. 83). Dessa maneira, a posição física do analista, também, é um elemento que conta, sobremaneira, para o bom andamento do tratamento. Nessa clínica, mesmo que o primeiro terapeuta tome a cena, ele sempre o fará em uma posição localizada algumas vezes ao lado da criança, muitas vezes atrás dela, permitindo que o som da voz do terapeuta e sua presença sejam suportáveis e evite-se uma crise. Do mesmo modo, se para a criança se faz necessária, a presença da mãe ou de qualquer outro familiar é considerada no atendimento.

Considerando a particularidade do trabalho psicanalítico com crianças autistas, Maleval (2014) também nos orienta quanto às condições para a abertura do ato analítico, acolhendo a excentricidade, que dará lugar a construções e produções do autista. Ainda no que diz respeito à particularidade dessa clínica, o setting analítico se faz em qualquer lugar onde a criança o sinta como suportável. A estandardização não é nossa proposta. No entanto, crianças que não suportam permanecer dentro da sala de atendimento são acolhidas e escutadas fora dela, percorrendo, por exemplo, os vários caminhos no interior do campus. Caminhos, que, por mais variados que sejam, mesmo assim, determinam sua lógica de funcionamento - basta ser ouvido e acolhido pelo terapeuta. Não estamos ali para produzir o significante que os ajudará a regrar seu mundo subjetivo, diz-nos Alkmim (2003), mas para dizer sim ao valor de seu achado. O saber está do lado do sujeito; o não saber, do nosso.
A operacionalização dessa clínica, como afirma Guerra (2003), nos indica que é preciso operar a partir da relação particular que cada sujeito mantém com o Outro. Assim, a transferência, a repetição ${ }^{7}$ e a pulsão ${ }^{8}$ não deixam de estar no lugar central da construção dos casos envolvidos com essa prática. Ademais, tem-se como objetivo não só buscar o entendimento teórico dessa clínica, mas avaliar, recorrentemente, $\mathrm{o}$ alcance de nossa técnica e buscar a melhor forma de intervir e escutar o sofrimento psíquico desse Outro no tratamento.

\section{Considerações finais}

Frente aos desafios tanto em âmbito geral da Reforma Psiquiátrica quanto no âmbito específico da clínica infanto-juvenil, fez-se urgente constituir novas modalidades da clínica por meio de dispositivos distintos tanto da psicanálise pura como dos dispositivos clássicos de internação e medicalização da existência. Pensamos a especificidade da clínica nos serviços substitutivos, ultrapassando práticas educacionais, que reduzem a clínica à mera adaptação ideologicamente determinada, para estabelecer uma prática que considere as práticas educativas a partir da singularidade subjetiva, sem reduzir o tratamento a uma adaptação. Nessa modalidade clínica, esperamos localizar as próprias estratégias defensivas do sujeito, para, a partir delas, sustentar a invenção de novas modalidades de extensão simbólica, que franqueiem o laço social dos sujeitos ditos autistas. Assim, a clínica não se coloca numa posição de antítese necessária a práticas educativas.

Por isso, no que concerne à práxis psicanalítica e sua especificidade, nesta clínica entre os muros da Universidade, investimos na construção de um método com critérios e técnicas de atendimento a crianças autistas fundamentados no saber psicanalítico. Ainda nesta empreitada, objetivamos uma instituição que funcione orientada pelo sujeito em questão. Afinal, é preciso produzirmos um trabalho analítico que se distancie daquele historicamente originado na história da psicanálise: o trabalho individual restrito ao consultório.

Assim, na perspectiva de reafirmar a presença e a possibilidade da psicanálise no tratamento psicanalítico, foi implantada, em 2016, entre os muros da UFSJ, uma clínica de atendimento a crianças autistas

\footnotetext{
${ }^{7}$ Repetição provém do campo pulsional (conferir nota de rodapé seguinte), que tem o caráter de uma insistência conservadora e que se apresenta sistematicamente nos sintomas (Roudinesco \& Plon, 1994).

${ }^{8}$ Pulsão tornou-se um grande conceito da doutrina psicanalítica, definido como a carga energética que se encontra na origem da atividade motora do organismo e do funcionamento psíquico inconsciente (Roudinesco \& Plon, 1994).
} 
pela psicanálise, que foi nomeada, em 2019, como: Pintando o Setting - clínica do autismo. Além disso, como ampliação desse projeto terapêutico na Universidade, também vinculamos ao atendimento da criança autista, o atendimento a seus familiares, que buscam tratar as dificuldades inerentes ao diagnóstico dela. Ademais, uma oficina de musicalização já faz parte desse projeto, em que a música se apresenta como um mediador terapêutico importante no tratamento com crianças autistas.
Outros modos terapêuticos de tratamento a essas crianças estão sendo pensados, tais como a robótica e a computação, que, com a música, permitem a mediação e inserção dessas crianças em um mundo que pode ser menos intrusivo para elas. Portanto, o que necessitamos, sobremaneira, é que as redes sociais, os serviços e as revistas, indexadas ou não, frente a seu alcance no meio público, reiterem em uníssono essa especialidade de trabalho realizado pela psicanálise.

\section{Referências}

Alkmim, W. (2003, novembro). Construir o caso clínico: A instituição enquanto exceção. Almanaque de Psicanálise e Saúde Mental, (9), 443-446.

Baio, V. (2007). Invenções do sujeito e de um parceiro na prática entre vários. In V. A. Ribeiro (Trad.), Pertinências da psicanálise aplicada: Trabalhos da Escola da Causa Freudiana reunidos pela Associação do Campo Freudiano (pp. 167-173). Forense Universitária.

Barroso, S. F. (2014). As psicoses na infância: O corpo sem a ajuda de um discurso estabelecido. Scriptum.

Bercherie, P. (1992). A clínica psiquiátrica da criança: Estudo histórico. Fhemig, (7), 20-38.

Campos, R. T. O. (2001). Clínica: A palavra negada - sobre as práticas clínicas nos serviços substitutivos de saúde mental. Saúde em Debate, 25(58), 98-111.

Ciaccia, A. D. (2007). Inventar a psicanálise na instituição. In V. A. Ribeiro (Trad.), Pertinências da psicanálise aplicada: Trabalhos da Escola da Causa Freudiana Reunidos pela Associação do Campo Freudiano (pp. 69-75). Forense Universitária.

Dolto, F. (2010). O caso Dominique. Martins Fontes.

Figueiredo, A. C. (2004, março). A construção do caso clínico: Uma contribuição da psicanálise à psicopatologia e à saúde mental. Revista Latino-americana de Psicopatologia Fundamental, 7(1), 75-86. https://doi.org/10.1590/1415-47142004001006

Freud, S. (1980). A Interpretação dos sonhos. In S. Freud, Edição standard brasileira das obras psicológicas completas de S. Freud (Vol. IV-V). Imago. (Obra original publicada em 1900)

Freud, S. (1980). Três Ensaios da Teoria da Sexualidade. In S. Freud, Obras Completas. Edição Standard Brasileira das obras psicológicas completas de S. Freud (Vol. 7). Imago. (Obra original publicada em 1905)

Freud, S. (1980). Sobre a dinâmica da Transferência. In S. Freud, Obras Completas. Edição Standard Brasileira das obras psicológicas completas de S. Freud (Vol. 12). Imago. (Obra original publicada em 1912)

Freud, S. (1980). História do Movimento Psicanalítico. In S. Freud, Obras Completas. Edição Standard Brasileira das obras psicológicas completas de S. Freud (Vol. 14). Imago. (Obra original publicada em 1914)

Freud, S. (1980). Linhas de Progresso da Terapia Psicanalítica. In S. Freud, Obras Completas. Edição Standard Brasileira das obras psicológicas completas de S. Freud (Vol. 17). Imago.. (Obra original publicada em 1919)

Freud, S. (1980). Mal-estar na civilização. In S. Freud, Obras Completas. Edição Standard Brasileira das obras psicológicas completas de S. Freud (Vol. 21). Imago. (Obra original publicada em 1929)

Freud, S. (1980). Psicologia das massas e análise do eu. In S. Freud, Edição Standard Brasileira das obras psicológicas completas de S. Freud (Vol. XVIII). Imago. (Obra original publicada em 1921)

Ferreira, T., \& Vorcaro, A. (2017). O tratamento psicanalítico de crianças autistas: Diálogo com múltiplas experiências. Autêntica.

Guerra, A. M. C. (2003). Tecendo a rede na assistência em Saúde Mental Infanto-juvenil: interfaces entre a dimensão clínica e a dimensão política. In A. M. C. Guerra \& N. L. Lima, A clínica de crianças com transtornos no desenvolvimento: Uma contribuição no campo da Psicanálise e da Saúde Mental (pp. 171-189). Fumec. 
Harari, A. Clínica lacaniana das psicoses: De Clérambault à inconsistência do Outro. Contracapa, 2006.

Julien, P. Psicose, perversão, neurose. Companhia de Freud, 2002.

Kyrillos Neto, F., \& Calazans, R. (2012). Questões preliminares para a clínica da psicose em serviços substitutivos de saúde mental. In S. M. Barroso \& F. Scorsolini-Comin (Orgs.), Diálogos em Psicologia (la ed., Vol. 1, pp. 220-233). Editora da Universidade Federal do Triângulo Mineiro.

Kupfer, M. C., \& Pinto, F. N. (2010). Lugar de vida, vinte anos depois. Escuta.

Kupfer, M. C., Jerusalinsky, A. N., Bernardino, L. M. F., Wanderley, D., Rocha, P. S. B., Molina, S. E. Sales, L. M., Stellin, R., Pesaro, M. E., \& Lerner, R. (2009). Valor preditivo de indicadores clínicos de risco psíquico para o desenvolvimento infantil: Um estudo a partir da teoria psicanalítica [Inédito].

Kusnierek, M. (2007). No caso a caso - Pertinências e limites da prática entre vários. In V. A. Ribeiro (Trad.), Pertinências da psicanálise aplicada: Trabalhos da Escola da Causa Freudiana reunidos pela Associação do Campo Freudiano (pp. 161-166). Forense Universitária.

Lacan, J. (1998). De uma questão preliminar a todo tratamento possível da psicose. In J. Lacan, Escritos (pp. 537-590). Jorge Zahar. (Obra original publicada em 1959)

Laurent, E, (2014). A batalha do autismo: da clínica à política. Jorge Zahar.

Lefort, R., \& Lefort, R. (1984). Nascimento do outro: Duas psicanálises (Biblioteca Freudiana Brasileira, Vol. 3). Fator.

Letra Freudiana. (1995). O Autismo. Letra Freudiana: Escola, psicanálise e Transmissão, 14(14).

Mannoni, M. (1981). A criança atrasada e a mãe. Moraes Editores.

Maleval, J.-C. (2014). Pourquoi l'hypothèse d'une structure autistique? (I). La cause du désir, (87), 167-173.

Maleval, J-C. (2017). O autista e sua voz. Blucher.

Miller, J.-A. (1994). C.S.T. In IRMA, Clínica lacaniana: Casos clínicos do campo lacaniano (pp. 9-15). Jorge Zahar.

Naveau, P. (2007). A Psicanálise aplicada ao sintoma: O que está em jogo e problemas. In V. A. Ribeiro (Trad.), Pertinências da psicanálise aplicada: Trabalhos da Escola da Causa Freudiana reunidos pela Associação do Campo Freudiano (pp. 9-16). Forense Universitária.

Paravidini, J. L. L., Próchno, C. C. S. C., Perfeito, H. C. C. S., \& Chaves, L. de S. Atendimento psicoterapêutico conjunto pais-crianças: Espaço de circulação de sentidos. Estilos da Clínica, 14(26), 90-105.

Pontes, S. P. C., Lopes, L., Santos, L. M. M. dos, \& Calazans, R. (2014). Implantação de políticas públicas em saúde mental: o caso de São João del Rei. Gerais: Revista Interinstitucional de Psicologia, 7(2), 260-268.

Quinet, A. (2006). Psicose e laço social. Jorge Zahar.

Ribeiro, J. M. de L. C. (2005). A criança autista em trabalho. 7letras.

Ribeiro, M. A. (2001). Editorial. Revista Marraio, 2.

Roudinesco, E., \& Plon, M. (1994). Dicionário de Psicanálise. Jorge Zahar.

Ruiz, V. S., Athayde, V., Nogueira Filho, I., Zambroni-de-Souza, P. C., \& Athayde, M. (2013). François Tosquelles, sua história no campo da Reforma Psiquiátrica / Desinstitucionalização e suas pistas para uma abordagem clínica do trabalho centrada na atividade. Revista Estudos e Pesquisas em Psicologia, 13(3), 855-877. https://doi.org/10.12957/epp.2013.8596

Stevens, A. (2007). Ainstituição: Prática do ato. InV. A. Ribeiro (Trad.), Pertinências da psicanálise aplicada: Trabalhos da Escola da Causa Freudiana reunidos pela Associação do Campo Freudiano (pp. 76-85). Forense Universitária.

Viganò, C. (1999, setembro). A construção do caso clínico em saúde mental. Curinga, (13), 39-48.

Viganò, C. (2010). A construção do caso clínico. Opção Lacaniana Online, 1(1), 1-9.

Vorcaro, A. (2004). Método psicanalítico e a clínica do laço mãe-bebê. Estilos da Clínica, 9(16), 70-79.

Vorcaro, A., Vilela, A. A. M., \& Oliveira, F. N. (2012). O que os bichos nos ensinam: A construção do caso clínico em um Centro de Atenção Psicossocial infanto-juvenil. CliniCAPS, 6(16), 37-49.

Zenoni, A. (2000). Psicanálise e instituição: A segunda clínica lacaniana. Abrecampos: Revista de Saúde Mental do Instituto Raul Soares, 1(0). 


\section{Maria Gláucia Pires Calzavara}

Professora Associada do Departamento de Psicologia da Universidade Federal de São João del-Rei (UFSJ), São João del-Rei - MG, Brasil. Doutora em Educação e Psicanálise pela Universidade Federal de Minas Gerais (UFMG), Belo Horizonte - MG, Brasil. Membro do Programa de Pós-Graduação em Psicologia (PPGPSI/UFSJ).

E-mail: glauciacalzavara@gmail.com

(1) https://orcid.org/0000-0002-4774-1397

\section{Roberto Calazans}

Professor Associado IV da Universidade Federal de São João del-Rei (UFSJ), São João del-Rei - MG, Brasil. Doutor em Teoria Psicanalítica pela Universidade Federal do Rio de Janeiro (UFRJ), Rio de Janeiro - RJ, Brasil. Realizou Estágio Pós-Doutoral no Programa de Pós-Graduação em Psicologia da UFMG em 2021.

E-mail: roberto.calazans@gmail.com

(1) http:/ /orcid.org/0000-0002-1455-2143

Endereço para envio de correspondência:

Universidade Federal de São João del-Rei. Praça Dom Helvécio, 74, Campus Dom Bosco. Departamento de Psicologia, sala 1.22. Bairro Dom Bosco. CEP: 36301-160. São João del-Rei, Minas Gerais - MG. Brasil.

Recebido 20/12/2019

Aceito 22/03/2021

Received 12/20/2019

Approved 03/22/2021

Recibido 20/12/2019

Aceptado 22/03/2021

Como citar: Calzavara, M. G. P., \& Calazans, R. (2022). A partir dos muros da universidade: Implementação de uma clínica psicanalítica para crianças autistas. Psicologia: Ciência e Profissão, 42, 1-14.

https://doi.org/10.1590/1982-3703003232410

How to cite: Calzavara, M. G. P., \& Calazans, R. (2022). From the walls of the university: Implementation of a psychiatric clinic for autistic children. Psicologia: Ciência e Profissão, 42, 1-14. https://doi.org/10.1590/1982-3703003232410

Cómo citar: Calzavara, M. G. P., \& Calazans, R. (2022). Más allá de los muros de la universidad: Implementación de una clínica psicoanalítica para niños autistas. Psicologia: Ciência e Profissão, 42, 1-14. https://doi.org/10.1590/1982-3703003232410 